\title{
FEASIBILITY VERIFICATION OF VIRTUAL REFERENCE STATION TECHNOLOGY IN GEOLOGICAL HAZARD MONITORING
}

\author{
ZHANG Qinglan ${ }^{1,2}$, CHEN Ming *2, WU Junli², XU Chaoqian ${ }^{3}$, WANG Fan ${ }^{2}$ \\ ${ }^{1}$ GNSS Research Center, Wuhan University, China \\ ${ }^{2}$ Dept of Geodesy, National Geomatics Center of China, China-(qlzhang, cm, jlwu, wangfan)@ngcc.cn \\ ${ }^{3}$ School of Geodesy and Geomatics, Wuhan University, China-cqxu@whu.edu.cn \\ KEY WORDS: CORS, Geological Disaster Monitoring and Early Warning, GNSS, VRS.
}

\begin{abstract}
:
The surveying and mapping administrative competent departments in 31 provinces (autonomous regions and municipalities) have built provincial-level satellite navigation and positioning reference stations and data centers, and provided CORS services. This provides a good condition for exploring the application of geological hazard monitoring and early warning using Virtual Reference Station (VRS) service based on CORS. At present, the layout mode of "one point one reference station" is usually adopted, when GNSS is used for geological disaster monitoring and early warning. However, the high deployment cost of this plan limits its largescale promotion and application. Using the existing CORS service resources of natural resource system, this paper carried out the application experiment of virtual reference station in geological hazard monitoring application at Huanglongya geological hazard monitoring site in Shaanxi Province, and assessed the virtual reference station data quality, comparative analyzed the precision of static baseline processing results and GNSS real-time deformation monitoring results. The experimental results show that the overall quality of virtual reference station data is better than that of the monitoring station, and the accuracy of the static baseline calculation results is better than $1.0 \mathrm{~cm}$ in the $\mathrm{X}$ direction, and better than $2.0 \mathrm{~cm}$ in the $\mathrm{Y}$ direction and $\mathrm{Z}$ direction, which is similar to the static baseline calculation results formed by the physical reference station. The accuracy of the baseline results of real-time observation data calculation is better than $5 \mathrm{~mm}$ in horizontal RMS and $15 \mathrm{~mm}$ in vertical RMS. Therefore, it can be seen that the virtual reference station is feasible to be used as the reference station for geological disaster monitoring. In addition, the application experiment of network RTK real-time dynamic single epoch positioning mode is also carried out in geological hazard monitoring. The experimental results show that the RMS values of all three directions are $\pm 3.7 \mathrm{~mm}, \pm 9.2 \mathrm{~mm}$ and $\pm 5.0 \mathrm{~mm}$ respectively, which meet the precision requirements of GNSS disaster monitoring. Therefore, it is also a feasible scheme for geological disaster monitoring and early warning.
\end{abstract}

China is a country with frequent occurrence of geological disasters. To carry out landslide geological disaster monitoring and timely release early warning information is the most effective means to avoid casualties and reduce economic losses For landslide, it is the most direct means to study and judge the real-time movement state of landslide by monitoring the surface displacement of landslide. GNSS, as a space-based radio navigation and positioning system, can provide users with allweather three-dimensional coordinates and speed at any place on the earth's surface or near earth space. With its remarkable advantages of global ground coverage, real-time, all-weather, three-dimensional coordinates with millimeter precision can be measured, and automation is easy to realize, GNSS has been widely used in landslide monitoring, and has become a key technology to obtain landslide information. It is one of the most important technical means of absolute displacement of body surface.

At present, GNSS technology used in geological disaster monitoring and early warning usually adopts the layout mode of "one point one reference station", which has high deployment cost and can not meet the needs of large-scale deployment of geological disaster monitoring and early warning in the future. Therefore, based on the existed CORS network resources in China, using virtual reference station (VRS) instead of physical reference station can greatly reduce the monitoring cost. Based on the VRS generated from the real-time observation data of CORS network, this study selected huanglongya landslide disaster area in Hanzhong City of Shaanxi Province to carry out the application verification of VRS technology in landslide geological disaster monitoring.

\section{REFERENCE STATIONS}

\subsection{Reference Stations}

At present, the Ministry of natural resources has built a national satellite navigation and positioning reference station network of 360 stations. The natural resources departments of 31 provinces (formerly the Department in charge of surveying, mapping and geographic information) have completed the construction of provincial satellite navigation and positioning reference station network covering their respective provincial areas, with a total of 2746 reference stations (with an average station spacing of $30-40 \mathrm{~km}$ in the eastern region and $60-70 \mathrm{~km}$ in the central and western regions) and 31 provincial data centers, and the realtime data transmission between the provincial data center and each reference station has been opened. The provincial CORS has been built, and the high-precision centimeter level navigation and positioning service coverage in all provinces has been achieved in real time. This also provides a good infrastructure for the application pilot and test of geological disaster monitoring based on the VRS technology of CORS.

\subsection{VRS Technology}

As the most widely used CORS service solution, VRS technology was first proposed and applied by Trimble terrasat in 2001, H Landau. The principle is that the data service center

\footnotetext{
* Corresponding author
} 
receives the observation data of all the physical reference stations in real time, and generates a VRS at the approximate position provided by the user. The observation data of the VRS is that the data center uses the precise known coordinates and real-time observation data of the physical reference stations around the user (at least three stations) to model the tropospheric delay and ionospheric delay, so as to calculate and simulate the tropospheric delay The observation data of virtual reference station is sent to the user terminal according to the standard RTCM format ( $\mathrm{rtcm} 3.3$ at present), so as to realize the centimeter level high-precision real-time positioning. At the same time, the VRS observation data can be stored locally for post positioning calculation, and the post millimeter level positioning accuracy can be obtained. The principle of VRS technology is shown in Figure 1:

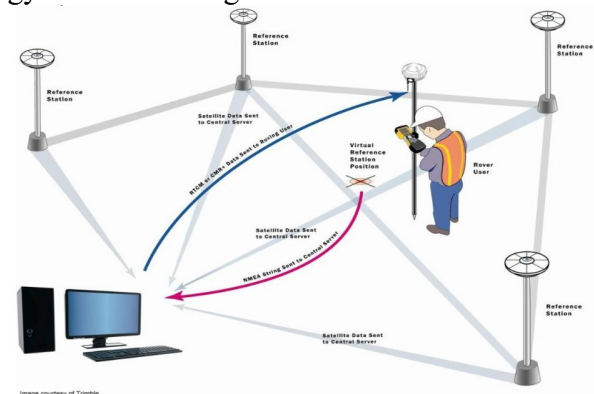

Figure 1. VRS application diagram

\subsection{Basic principles of VRS}

Picture from Trimble)

\subsubsection{VRS mathematical model}

At present, Trimble is one of the typical representatives of VRS research and application, which is early and widely used. After VRS technology was put forward, many international and domestic institutions and experts have carried out in-depth research on it, and successfully realized its commercial application and industrialization. The establishment process and mathematical model of VRS proposed by Trimble are as follows:

1) Data acquisition of reference station

Firstly, based on the following observation equations (1) - (4), the integrity of pseudo range and carrier phase observations collected by each reference station is checked.

$$
\begin{aligned}
& \rho_{1}^{\mathrm{s}}(\mathrm{t})=\mathrm{R}^{\mathrm{s}}(\mathrm{t})+\mathrm{I}^{\mathrm{s}}(\mathrm{t})+\Delta \mathrm{t}_{\mathrm{r}}(\mathrm{t})-\Delta \mathrm{t}^{\mathrm{s}}(\mathrm{t})+\mathrm{T}^{\mathrm{s}}(\mathrm{t})+\mathrm{v}_{1}^{\mathrm{s}}(\mathrm{t}) \\
& \rho_{2}^{\mathrm{s}}(\mathrm{t})=\mathrm{R}^{\mathrm{s}}(\mathrm{t})+\mathrm{I}^{\mathrm{s}}(\mathrm{t}) \frac{\lambda_{2}^{2}}{\lambda_{1}^{2}}+\Delta \mathrm{t}_{\mathrm{r}}(\mathrm{t})-\Delta \mathrm{t}^{\mathrm{s}}(\mathrm{t})+\mathrm{T}^{\mathrm{s}}(\mathrm{t})+\mathrm{v}_{1}^{\mathrm{s}}(\mathrm{t}) \\
& \lambda_{1}\left(\phi_{1}^{\mathrm{s}}(\mathrm{t})+\mathrm{N}_{1}^{\mathrm{s}}\right)=\mathrm{R}^{\mathrm{s}}(\mathrm{t})-\mathrm{I}^{\mathrm{s}}(\mathrm{t})+\Delta \mathrm{t}_{\mathrm{r}}(\mathrm{t})-\Delta \mathrm{t}^{\mathrm{s}}(\mathrm{t})+\mathrm{T}^{\mathrm{s}}(\mathrm{t})+\mathrm{w}_{1}^{\mathrm{s}}(\mathrm{t}) \\
& \lambda_{2}\left(\phi_{2}^{\mathrm{s}}(\mathrm{t})+\mathrm{N}_{2}^{\mathrm{s}}\right)=\mathrm{R}^{\mathrm{s}}(\mathrm{t})-\mathrm{I}^{\mathrm{s}}(\mathrm{t}) \frac{\lambda_{2}^{2}}{\lambda_{1}^{2}}+\Delta \mathrm{t}_{\mathrm{r}}(\mathrm{t})-\Delta \mathrm{t}^{\mathrm{s}}(\mathrm{t})+\mathrm{T}^{\mathrm{s}}(\mathrm{t})+\mathrm{w}_{1}^{\mathrm{s}}(\mathrm{t})
\end{aligned}
$$

Where, $\rho_{1}^{\mathrm{s}}(\mathrm{t})$ and $\phi_{1}^{\mathrm{s}}(\mathrm{t})$ respectively represent the pseudo range and carrier phase observation data of the satellite $\mathrm{s}$ at time t. $\lambda_{1}, \mathrm{~N}_{1}^{\mathrm{S}}$ and $\mathrm{R}^{\mathrm{S}}(\mathrm{t})$ denote the wavelength of carrier $\mathrm{L} 1$, the ambiguity of carrier phase value and the geometric distance of receiving satellite $\mathrm{s}$ at time $\mathrm{t} ; \mathrm{I}^{\mathrm{S}}(\mathrm{t})$ and $\mathrm{T}^{\mathrm{S}}(\mathrm{t})$ denote the ionospheric and tropospheric delay of satellite $s$ at time $t$; $\Delta \mathrm{t}_{\mathrm{r}}(\mathrm{t})$ and $\Delta \mathrm{t}^{\mathrm{S}}(\mathrm{t})$ denote the receiver clock error and satellite clock error at time $\mathrm{t} ; \mathrm{v}_{1}^{\mathrm{s}}(\mathrm{t})$ and $\mathrm{w}_{1}^{\mathrm{s}}(\mathrm{t})$ denote the measurement noise (and multipath effect, etc.). the robustness of receiver clock error is estimated for checking the integrity of pseudo range observations.

The observation equation is differed between stations, which removes the common satellite clock difference between two stations. It can greatly weakens the errors whicn related to distance, and improves the detection accuracy of observation integrity.

2) Errors simulation

The VRS mathematical model mainly simulates the effects of multipath error, ionospheric delay, tropospheric delay and orbit error. The repeatability of multi-path effect is used to simulate for multi-path error model; The two-dimensional zenith ionospheric delay model based on geomagnetic latitude and solar time angle is used for ionospheric error simulation (see equation 5 for details).

$$
\operatorname{TEC}\left(\phi_{\text {mag }}, \lambda_{\text {sun }}\right)=\sum_{\mathrm{k}=0 \mathrm{t}=0}^{\mathrm{N}} \sum_{\mathrm{A}_{\mathrm{i}, \mathrm{k}}}^{\mathrm{k}} \phi_{\text {mag }}^{\mathrm{i}} \lambda_{\text {sun }}^{\mathrm{k}-\mathrm{i}}
$$

The simulation mathematical model of orbit error and tropospheric delay based on the geometric relationship between stations and satellites is shown in equation (see equation 6)

$$
\lambda_{1}\left(\phi_{c}^{s}(t)+N_{c}^{s}\right)=R^{s}(t)+\Delta t_{r}(t)-\Delta t^{s}(t)+Z_{1}^{s}(t)+T_{r} T M_{r}^{s}(t)+\frac{\Delta X^{S} R^{s}(t)}{R^{s}(t)}
$$

In the above formula, $\phi_{\mathrm{c}}^{\mathrm{S}}(\mathrm{t}), \mathrm{N}_{\mathrm{c}}^{\mathrm{s}}$ and $\mathrm{TS}_{\mathrm{r}}$ denote the phase observation value without ionosphere influence, the integer ambiguity and the influence factors of receiver $r$ on the process; $\mathrm{TM}_{\mathrm{r}}^{\mathrm{S}}(\mathrm{t}), \Delta \mathrm{X}^{\mathrm{S}}$ and $\mathrm{R}^{\mathrm{S}}(\mathrm{t})$ denote the tropospheric model value and the vector from satellite $\mathrm{s}$ orbit to receiver.

3) Generation of VRS

The first step of VRS generation is to correct the ambiguity of the baseline in the CORS, so that the positioning error of the observation value can be maintained in centimeter level accuracy. Specifically, the data of a reference station (usually the nearest reference station to the user) in the network is selected to simulate the data of the virtual reference station, and then the simulation errors are interpolated into the observation data of the virtual reference station.

Trimble uses variance covariance method to correct the ambiguity in VRS generation. The interpolation method of simulation error adopts linear two-dimensional model, which is to triangulate the network of reference station, and then establish a linear model for the difference error between three reference stations which constitute each triangle.

1.3.2. Application process of VRS in geological disaster monitoring

The basic principle of application of disaster monitoring based on VRS is to select suitable site position around the landslide monitoring area as the general coordinate of VRS, Then, the observation data of at least 3 reference stations selected nearby and the general coordinates of VRS are sent to the data center to generate VRS observation data. Then, the VRS observation data and the earth disaster monitoring station observation data are connected to the disaster monitoring platform, and the ultra short baseline solution is carried out to monitor the displacement change of the ground disaster monitoring station relative to VRS, so as to realize landslide monitoring Measurement and early warning. 


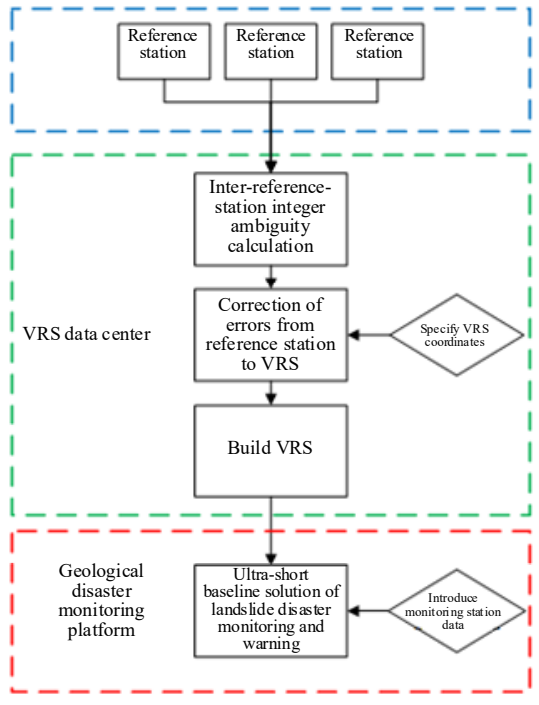

Figure 2. Technical process of VRS used in geological disaster monitoring

\subsection{Advantages of VRS}

1) Reduce monitoring cost significantly: for the areas with frequent geological disasters, such as the virtual reference station established by VRS technology, the number of geological disaster monitoring areas can be far greater than the number of physical reference stations in theory, thus reducing the cost of building stations.

2) Positioning accuracy more uniform: in the positioning by VRS technology, the concept of ppm with linear correlation between precision and baseline length no longer exists, so within the coverage of VRS service, the terminal positioning accuracy can always be kept at $1-2 \mathrm{~cm}$.

3) Improve positioning reliability: in the small area geological disaster monitoring area, the failure of the reference station in the conventional scheme will cause all monitoring points to be unable to carry out relative positioning, so the positioning accuracy will be reduced to the meter level precision of pseudo distance single point positioning. The reliability of VRS is related to the reliability of the whole CORS network.

4) The monitoring network layout more flexible and reasonable: since the virtual reference station is not built on the real ground, the coordinate stability of the reference station is theoretically not affected by the surrounding geological environment. We can generate virtual reference station at any position in the monitoring area or enven in the central position of the whole monitoring area, making the whole monitoring network more reasonable and minimizing the difference of the length of the side between the reference station and each supervision station as far as possible.

\section{Verification Scheme}

\subsection{Experimental Area and Data}

For purpose of the feasibility verification, Huanglongya landslide monitoring area in Hanzhong of Shaanxi Province is selected as experimental area. The landslide is about $200 \mathrm{~m}$ long and $100 \mathrm{~m}$ wide, the slope is $30^{\circ}$, it is a soil landslide, and the main risk point is National Highway 108 that is located in the accumulation area. In the landslide area, the minimum lighting time at all seasons is 10 hours, the mobile $4 \mathrm{G}$ signal is strong, there is no large-scale building or large-area water body nearby, but there are high-power radio transmission sources nearby. Based on the survey results, 3 sets of GNSS displacement monitoring stations are installed along the principal section line of the landslide, CHC H3 GNSS receiver and HX-SX031A antenna are adopted.

Depending on the distribution of the satellite navigation and positioning reference stations built in the natural resource system, 7 physical reference stations among which the mean station distance is $60 \mathrm{~km}$ around Huanglongya landslide monitoring site are selected to generate VRS station GHLY. Table 2 shows information of the reference stations around the landslide site, and Figure 2 shows relative position relationships of the reference stations.

Table 2. CORS station information around the landslide site

\begin{tabular}{|c|c|c|c|c|c|}
\hline $\begin{array}{c}\text { Serial } \\
\text { number }\end{array}$ & $\begin{array}{c}\text { Station } \\
\text { name }\end{array}$ & Code & $\begin{array}{c}\text { Receiver } \\
\text { type }\end{array}$ & $\begin{array}{c}\text { Antenna } \\
\text { type }\end{array}$ & $\begin{array}{c}\text { Antenna } \\
\text { height } \\
(\mathbf{m})\end{array}$ \\
\hline 1 & $\begin{array}{c}\text { Hanzhong } \\
\text { Lueyang }\end{array}$ & DZLY & $\begin{array}{c}\text { TRIMBLE } \\
\text { NETR9 }\end{array}$ & $\begin{array}{c}\text { TRM59900.00 } \\
\text { SCIS }\end{array}$ & 0.140 \\
\hline 2 & $\begin{array}{c}\text { Hanzhong } \\
\text { Mianxian }\end{array}$ & DZMX & $\begin{array}{c}\text { TRIMBLE } \\
\text { NETR9 }\end{array}$ & $\begin{array}{c}\text { TRM59900.00 } \\
\text { SCIS }\end{array}$ & 0.142 \\
\hline 3 & $\begin{array}{c}\text { Hanzhong } \\
\text { Ningqiang }\end{array}$ & HZNQ & $\begin{array}{c}\text { TRIMBLE } \\
\text { ALLOY }\end{array}$ & $\begin{array}{c}\text { TRM159900.00 } \\
\text { SCIS }\end{array}$ & 0.075 \\
\hline 4 & $\begin{array}{c}\text { Hanzhong } \\
\text { Nanzheng }\end{array}$ & HZNZ & $\begin{array}{c}\text { TRIMBLE } \\
\text { ALLOY }\end{array}$ & $\begin{array}{c}\text { TRM159900.00 } \\
\text { SCIS }\end{array}$ & 0.075 \\
\hline 5 & $\begin{array}{c}\text { Hanzhong } \\
\text { Liuba }\end{array}$ & HZLB & $\begin{array}{c}\text { TRIMBLE } \\
\text { ALLOY }\end{array}$ & $\begin{array}{c}\text { TRM159900.00 } \\
\text { SCIS }\end{array}$ & 0.075 \\
\hline 6 & $\begin{array}{c}\text { Hanzhong } \\
\text { Chenggu }\end{array}$ & HZCG & $\begin{array}{c}\text { TRIMBLE } \\
\text { ALLOY }\end{array}$ & $\begin{array}{c}\text { TRM159900.00 } \\
\text { SCIS }\end{array}$ & 0.075 \\
\hline 7 & $\begin{array}{c}\text { Baoji } \\
\text { Fengxian }\end{array}$ & SNFX & $\begin{array}{c}\text { TRIMBLE } \\
\text { ALLOY }\end{array}$ & $\begin{array}{c}\text { TRM59900.00 } \\
\text { SCIS }\end{array}$ & 0.075 \\
\hline
\end{tabular}

Based on the real-time observation data flow of the 7 reference stations mentioned above, a small-scale reference station network is built with network RTK solution software for data solution, and real-time VRS station GHLY data is generated in the central location of the landslide site. Figure 3 shows relative positions of the 7 reference stations around the landslide site:

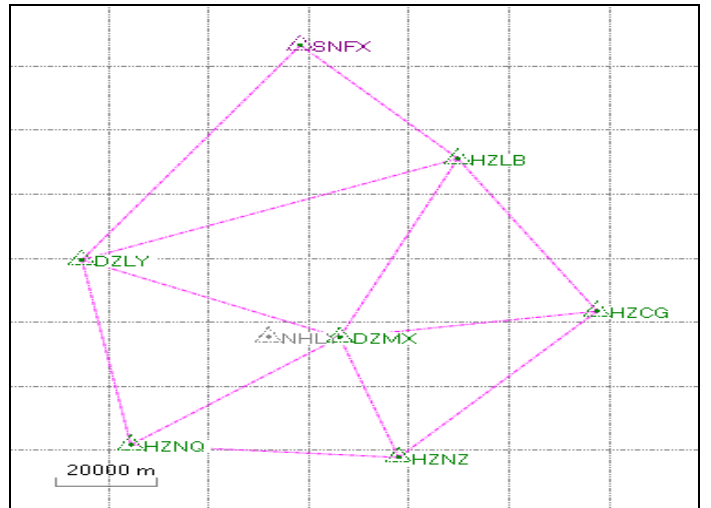

Figure 3 Distribution map of CORS stations around the landslide site

\subsection{Experimental Scheme Design}

The experiment is designed to verify the feasibility of VRS service in landslide monitoring based on VRS data quality evaluation analysis, static baseline solution result analysis, and real-time observation data processing result precision analysis. Additionally, the experiment is also intended for verifying the application feasibility of network RTK real-time dynamic single epoch positioning service in landslide monitoring.

\section{1) Observation data quality evaluation:}

Presently, GNSS observation data quality evaluation is generally subject to three main indicators, namely data integrity rate $\geq 85 \%$, multipath effect error $\mathrm{MP} 1<0.5 \mathrm{~m}$, and multipath effect error $\mathrm{MP} 2<0.5 \mathrm{~m}$, respectively. For purpose of the 
experiment, TEQC (Translate Edit Quality Check) software developed by UNACO is employed to evaluate VRS data for the indicators mentioned above. Besides, to evaluate the stability of VRS data, the GNSS high-precision processing software GAMIT is adopted in the experiment to perform networking solution of VRS data and 24-hour observation data of 7 CORS stations in Shannxi province to evaluate station positioning precision.

\section{2) Static baseline solution result analysis:}

For static baseline solution, TBC (Trimble Business Center, V5.0.2) software developed by Trimble is adopted, and observation data of 24 time intervals on the 196th day from the virtual reference station GHLY, physical reference station HLY1, and monitoring station HLY2 is selected. The baseline combination schemes include GHLY-HLY2 and HLY1-HLY2. The baseline processing strategies are as below:

Table 3. Static baseline solution strategies

\begin{tabular}{|c|c|}
\hline Parameter & Strategy \\
\hline Satellite signal & GPS+BDS multi-frequency \\
carrier observation signal \\
Satellite orbit & Precision orbit \\
Process interval & Auto \\
Antenna phase center & NGS-provided correction \\
correction & model \\
Solution type & Fixed solution \\
Elevation mask angle & $15^{\circ}$ \\
\hline
\end{tabular}

3) Real-time data processing result precision analysis;

For real-time data processing solution, a self-developed deformation monitoring platform is adopted, and the observation data of 9 days (from the 195th to the 203rd day) from the virtual reference station GHLY and monitoring station HLY2 is selected. The processing strategies adopted are as shown in Table 4:

Table 4. Real-time data processing strategies of selfdeveloped deformation monitoring platform

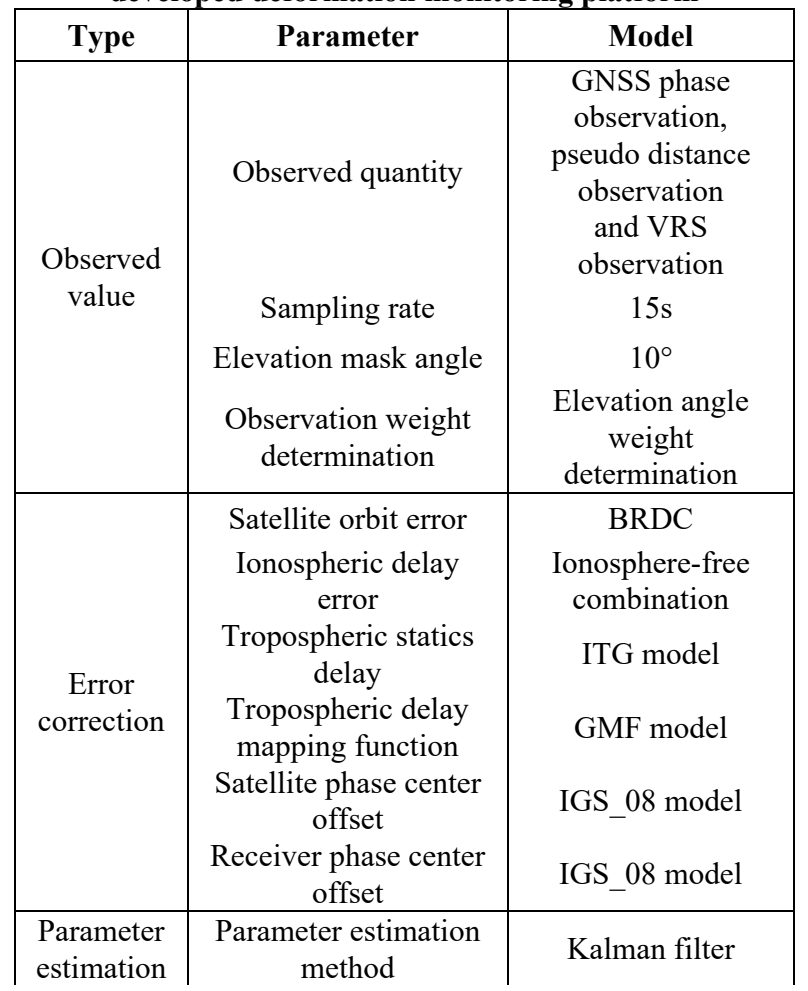

\begin{tabular}{|c|c|c|}
\hline Type & Parameter & Model \\
\hline & $\begin{array}{c}\text { Double-difference } \\
\text { integer ambiguity } \\
\text { Tropospheric wet } \\
\text { delay }\end{array}$ & $\begin{array}{c}\text { Estimation } \\
\text { Estimation } \\
\text { (random walk) }\end{array}$ \\
\hline $\begin{array}{c}\text { Processing } \\
\text { setup }\end{array}$ & Sliding window & $\begin{array}{c}\text { 1h, processing } \\
\text { frequency 5min }\end{array}$ \\
\hline
\end{tabular}

4) Network RTK real-time dynamic single epoch positioning mode:

For the experiment, SOUTH galaxy 1 receiver is taken as test terminal equipment, the positioning interval is 1second, the total test time is $1 \mathrm{~h}$, and network RTK service of VRS mode is adopted. The RMS of the difference between each epoch positioning result and the mean value is calculated to evaluate the application feasibility of this method in geological disaster monitoring. Figure 4 shows a picture of site test:

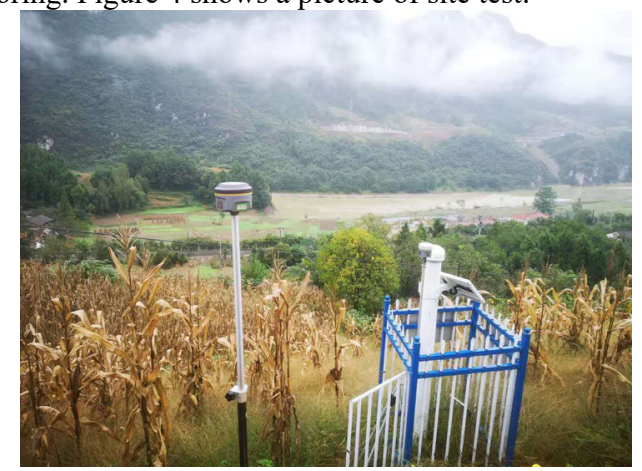

Figure 4. Test of using network RTK Dynamic single epoch positioning

\section{Experimental Result Analysis}

\subsection{VRS Data Quality}

\subsubsection{TEQC check}

The mean value of data integrity rate of all time intervals of the virtual reference station GHLY is $85 \%$, and the data integrity rate of the monitoring station HLY2 is around $50 \%-60 \%$; both the multipath effect error MP1 and MP2 of the virtual reference station GHLY are less than $0.5 \mathrm{~m}$, the data multipath effect error MP1 of the monitoring station HLY2 is less than $0.5 \mathrm{~m}$, but the multipath effect error MP2 of HLY2 is larger than $0.5 \mathrm{~m}$. The data quality of the virtual reference station is obviously better than that of the monitoring station. There are two main reasons. (1) The data quality of the virtual reference station is related to the data quality of CORS reference stations in the surrounding area; (2) Limited by the observation environment in the landslide site, the monitoring station is seriously blocked out, so that the observation data quality is relatively poor.

3.1.2. Static positioning result

Computing the united solution of the virtual reference station GHLY and 6 CORS stations in Shannxi shows that the coordinate solution result precision of all the stations is comparable, and the precision of inner coincidence in all directions is superior to $\pm 3 \mathrm{~cm}$ (see Table 5 for details).

Table 5. Statistical table of one-day solution (relaxation solution) satation coordinate precision (Unit: cm)

\begin{tabular}{|c|c|c|c|c|c|c|c|}
\hline & \multicolumn{6}{|c|}{ Shannxi CORS station } & VRS \\
\hline & DZLY & DZMX & HZCG & HZLB & HZNZ & SNF2 & GHLY \\
\hline $\mathrm{N}$ & 2.51 & 2.51 & 2.51 & 2.53 & 2.52 & 2.51 & 2.51 \\
\hline$E$ & 2.53 & 2.52 & 2.54 & 2.65 & 2.62 & 2.54 & 2.54 \\
\hline
\end{tabular}




\begin{tabular}{|l|l|l|l|l|l|l|l|}
\hline $\mathrm{U}$ & 2.60 & 2.59 & 2.65 & 2.68 & 2.83 & 2.66 & 2.68 \\
\hline
\end{tabular}

In addition, to evaluate the data stability of the virtual reference station and detect whether any individual epoch shows abnormal, statistical residual plots of the virtual reference station GHLY and Shannxi CORS station DZLY are developed in this experiment based on satellite arc segment (see Figure 5) and elevation angle (see Figure 6) respectively. The statistical results based on satellite arc segment show that GHLY residual RMS is $6.2 \mathrm{~mm}$, DZLY residual RMS is $7.8 \mathrm{~mm}$; the statistical results based on elevation angle show that GHLY residual RMS value in different elevation angle ranges is superior to that of DZLY. This indicates that the virtual reference station is superior to the physical reference station in respect of data quality, and comparable to the latter in respect of observation data stability and precision.
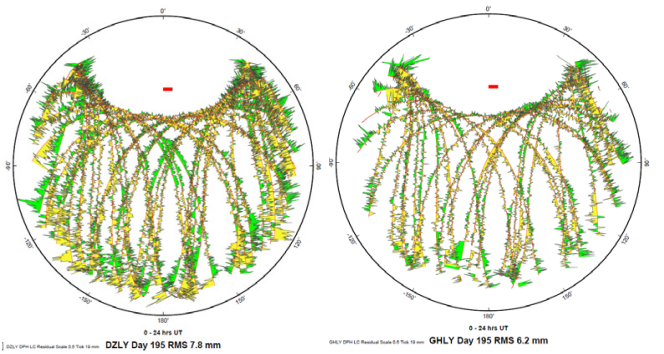

Figure 5. Residual plot of satellite arc segment observed at the site, left: Shannxi CORS station DZLY, right: virtual reference station GHLY
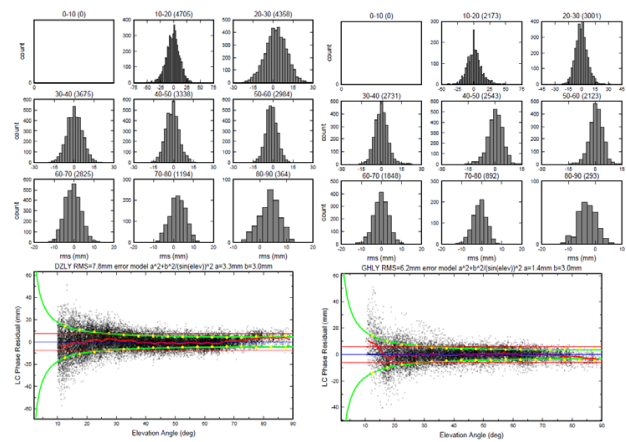

Figure 6. Observation data residual plot at various elevation angles of the site, left: Shannxi CORS station DZLY, right: virtual reference station GHLY

\subsection{Static Baseline Solution Results}

The mean value of GHLY-HLY2 baseline length is $37.589 \mathrm{~m}$. The computations for various time intervals show: the standard deviations of baseline $\Delta \mathrm{X}, \Delta \mathrm{Y}$ and $\Delta \mathrm{Z}$ are $\pm 3 \mathrm{~mm}, \pm 7 \mathrm{~mm}$ and $\pm 4 \mathrm{~mm}$ respectively, the difference between $\Delta \mathrm{X}$ and $\Delta \mathrm{Z}$ and their respective mean value is less than $1 \mathrm{~cm}$, and the difference between $\Delta \mathrm{Y}$ and the mean value in each time interval is basically less than $2 \mathrm{~cm}$, as shown in Figure 7;

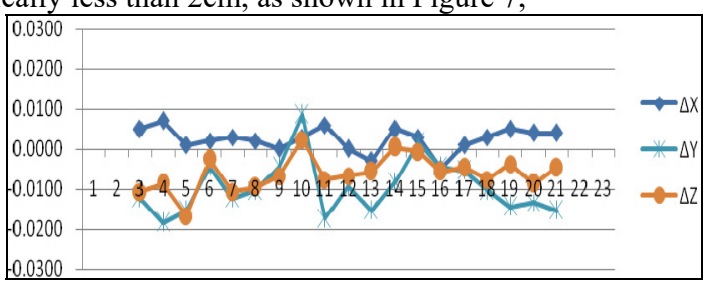

Figure 7. Changing trend of the difference between GHLY-HLY2 baseline component in each time interval and the mean value $(\mathrm{m})$
The mean value of HLY1-HLY2 baseline length is $37.475 \mathrm{~m}$. The computations for various time intervals show: the standard deviations of baseline $\Delta \mathrm{X}, \Delta \mathrm{Y}$ and $\Delta \mathrm{Z}$ are $\pm 4 \mathrm{~mm}, \pm 13 \mathrm{~mm}$ and $\pm 5 \mathrm{~mm}$ respectively, the difference between $\Delta \mathrm{X}$ and $\Delta \mathrm{Z}$ and their respective mean value is less than $1 \mathrm{~cm}$, and the difference between $\Delta \mathrm{Y}$ and the mean value in each time interval is basically less than $2 \mathrm{~cm}$. Besides, the observation data integrity of the monitoring reference station HLY1 in the 4th and 5th time intervals is merely $35 \%$, only 4 GPS satellite signals are received in many epochs, and the data precision of one satellite (PRN4) is poor and inapplicable, resulting that the baseline $\Delta \mathrm{Y}$ difference is slightly larger than $2 \mathrm{~cm}$, as shown in Figure 8;

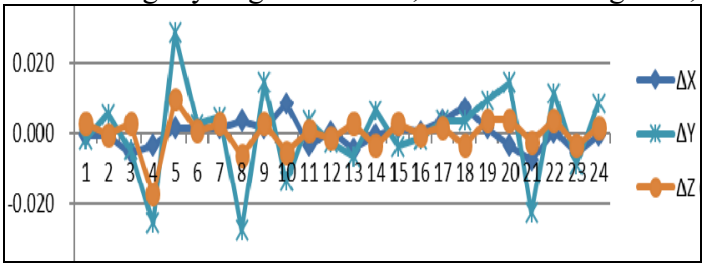

Figure 8. Changing trend of the difference between HLY1-

HLY2 baseline component in each time interval and the mean value (m)

\subsection{Real-time Data Processing Results}

The results show: The precision of inner coincidence of GHLYHLY2 baseline (1h sliding window) solution is better than $\pm 3 \mathrm{~mm}$ horizontally and $\pm 15 \mathrm{~mm}$ vertically. Table 6 shows precision details of baseline solution results, and Figure 9 shows the changing trend of solution results in various directions of the baseline;

Table 6. Statistics of precision of inner coincidence of realtime data processing results in various directions

\begin{tabular}{c|c|c}
\hline \multicolumn{2}{c|}{ Baseline } & STD(mm) \\
\hline GHLY- & $\mathrm{E}$ & 2.8 \\
HLY2 & $\mathrm{N}$ & 1.6 \\
& $\mathrm{U}$ & 7.5 \\
\hline
\end{tabular}
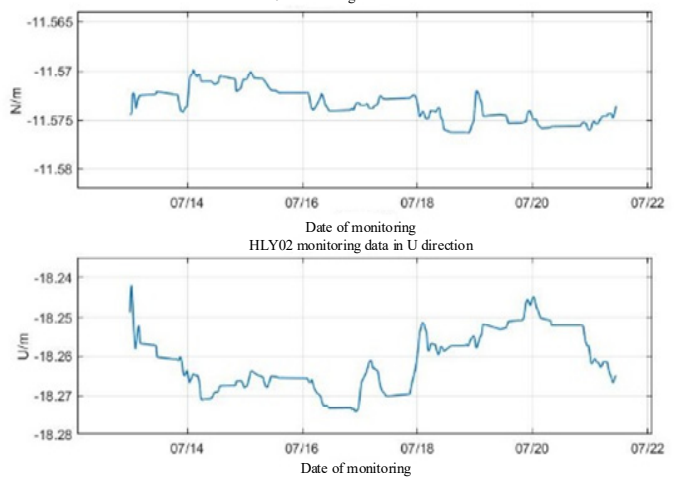

Figure 9. E、N、U sequence diagram of GHLY-HLY2 baseline solution

3.4. Network RTK Real-time Dynamic Single Epoch Positioning Test Results

The test results show: the RMS value of the precision of inner coincidence in directions $\mathrm{X}, \mathrm{Y}$ and $\mathrm{Z}$ of the point coordinates in the case a professional RTK measuring equipment is employed 
for network RTK real-time dynamic single epoch positioning is $\pm 5.04 \mathrm{~mm}, \pm 10.1 \mathrm{~mm}$ and $\pm 5.4 \mathrm{~mm}$ respectively, the difference between the positioning results in direction $\mathrm{X}$ and the mean value is basically better than $1 \mathrm{~cm}$, the difference between the positioning results in direction $\mathrm{Z}$ and the mean value is basically better than $2 \mathrm{~cm}$, and the difference between the positioning results in direction $\mathrm{Y}$ and the mean value is relatively large because direction $\mathrm{Y}$ is most related to the elevation direction, but basically remains within $\pm 4 \mathrm{~cm}$, as shown in Figure 10:

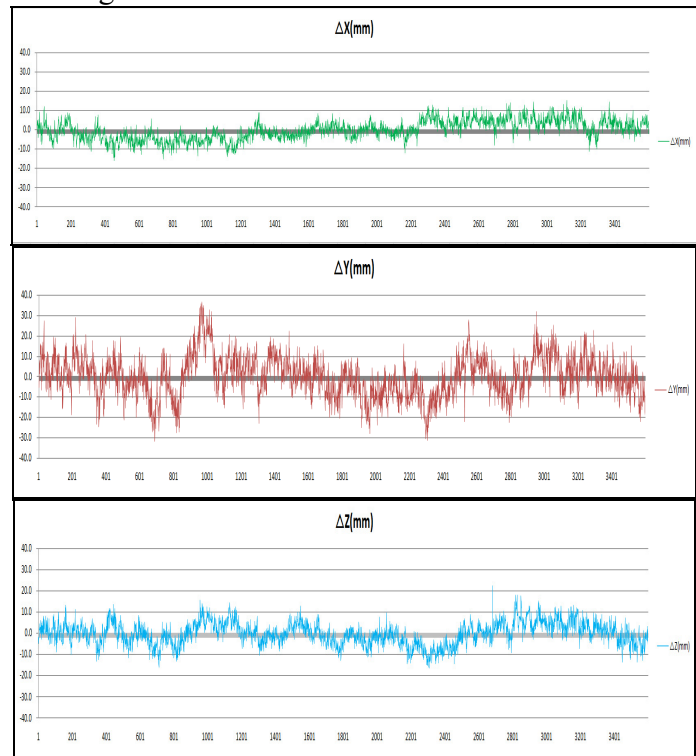

Figure 10. Sequence diagram of difference trend between directions $X, Y$ and $Z$ and their respective mean value

\section{CONCLUSION}

1). The virtual reference station is a little better than the physical reference station in the same area in respect of data integrity and multipath effect on the whole, and is comparable to the physical CORS stations in respect of data stability and positioning result precision, which indicates that virtual reference station meets with the requirements of geological disaster monitoring for observation data quality.

2). The virtual reference station is a little better than the physical reference station in respect of precision of static baseline solution results, which may be because the observation data quality of virtual reference station is good; the baseline solution results based on real-time observation data by means of sliding window (sliding window duration $1 \mathrm{~h}$ ) indicate that it is feasible to use virtual reference station as monitoring reference station.

3). It is also feasible to employ professional measurement-type terminal equipment to perform geological disaster monitoring and warning based on network RTK real-time dynamic single epoch positioning mode, but the cost of terminal is relatively high.

\section{ACKNOWLEDGEMENTS}

Research is supported by the National Natural Science Foundation of China (Grant No 41804038.) \& National Key Research and Development Program of China (No. 2016YFB0501405)

\section{REFERENCE}

Hofmann-Wellenhof B, Lichtenegger H, Wasle E. GNSSGlobal Navigation Satellite Systems: GPS, GLONASS, Galileo and More[M]. Berlin: Springe, 2008.

Lambert Wanninger. GPS On the Web: Vitual reference stations (VRS). Ingenieurburo Wanniger, Neuwied , Germany.

Gao Weixing Algorithm Research and Program Implementation of GPS/GLONASS Network RTK Doctoral Dissertation at Wuhan University 20020501

ChenMing,Wu Junli, Li Zhicai. Construction of the National GNSS Continuous Operation ReferenceSations[J].Geomatics World, 2018, 25(1):42-46

Hofmann-Wellenhof B, Lichtenegger H, Wasle E. GNSSGlobal Navigation Satellite Systems: GPS, GLONASS, Galileo and More[M]. Berlin: Springe, 2008.

Wu Beiping, Li Zhenghang, Xu Shaoquan. Application of GPS Satellite Positioning Technique To Monitoring of Landslides in Three Gorges Dam.[J]. Journal of Earth Science,2001,26 (6) : 648-652.

Han B , Tong B, Yan J , et al. The Monitoring-Based Analysis on Deformation-Controlling Factors and Slope Stability of Reservoir Landslide: Hongyanzi Landslide in the Southwest of China[J]. Geofluids, 2018, 2018:1-14.

ZHANGQin, HUANG Guanwen, YANG Chengsheng.Precision Space Observation Technique for Geological Hazard Monioring and Early warning. [J]. Journal of Geodesy and Geoinformation Science, 2017,46 (10): 1300-1307.

Han B , Tong B , Yan J, et al. The Monitoring-Based Analysis on Deformation-Controlling Factors and Slope Stability of Reservoir Landslide: Hongyanzi Landslide in the Southwest of China[J]. Geofluids, 2018, 2018:1-14. 